\title{
Comparison of molecular abnormalities in vulvar and vaginal melanomas
}

\author{
Sebastian Aulmann ${ }^{1,7}$, Hans P Sinn ${ }^{1,7}$, Roland Penzel ${ }^{1}$, C Blake Gilks ${ }^{2}$, Sarah Schott ${ }^{3}$, \\ Jessica C Hassel ${ }^{4}$, Dietmar Schmidt ${ }^{5}$, Friedrich Kommoss ${ }^{5}$, Peter Schirmacher ${ }^{1}$ and \\ Stefan Kommoss ${ }^{6}$ \\ ${ }^{1}$ Institute of Pathology, Heidelberg University Hospital, Heidelberg, Germany; ${ }^{2}$ University of British \\ Columbia, Department of Pathology and Laboratory Medicine, Vancouver, British Columbia, Canada; \\ ${ }^{3}$ Department of Gynecology, Heidelberg University Hospital, Heidelberg, Germany; ${ }^{4}$ Department of \\ Dermatology, Heidelberg University Hospital, Heidelberg, Germany; ${ }^{5}$ Institute of Pathology, Mannheim, \\ Germany and ${ }^{6}$ Department of Gynecology, Tuebingen University Hospital, Tuebingen, Germany
}

\begin{abstract}
Malignant melanoma of the vulva and vagina is relatively uncommon and accounts for $<5 \%$ of all melanomas in women. The aim of our study was to establish the biological properties and evaluate potential therapeutic targets in these tumors. We collected a series of 65 cases from three centers and re-evaluated the tumor tissue for predominant growth pattern (superficial spreading, nodular, and mucosal lentiginous) and tumor thickness. KIT (CD117) expression was detected immunohistochemically. In addition, tumors were screened for BRAF, NRAS, and KIT mutations by PCR and DNA sequencing as well as for KIT amplifications by fluorescence in situ hybridization. None of the cases contained BRAF mutations. NRAS mutations and KIT amplifications were detected in similar frequency $(\sim 12 \%)$ in tumors of the vulva and vagina. In contrast, KIT mutations were present in $18 \%$ of primary melanomas of the vulva, but in none of the tumors arising in the vagina. Moderate or strong KIT protein expression was detected in 30 cases, including all tumors with KIT mutations and 6 of the 7 with KIT amplifications. In conclusion, BRAF mutations are virtually absent in melanomas originating from the vulva or vagina, whereas NRAS mutations and KIT amplifications occur in both locations. KIT mutations appear to be specific for melanomas of the vulva, suggesting that in spite of the anatomic proximity, the development of vulvar and vaginal melanomas involves different molecular alterations which may be targeted by novel treatment approaches.
\end{abstract}

Modern Pathology (2014) 27, 1386-1393; doi:10.1038/modpathol.2013.211; published online 7 March 2014

Keywords: melanoma; mutation; pathology

Malignant melanoma of the vulva and vagina are uncommon tumors representing $<1 \%$ of all female genital tract malignancies. Typically, older women are affected; in population-based series, an average patient age of 70 years has been reported. ${ }^{1}$ Overall prognosis largely depends on tumor stage and is poor in cases with an increased tumor thickness, ulceration, or lymph node metastases. ${ }^{2,3}$

Recently, there has been a substantial increase in understanding the biology of malignant melanoma. It has become clear that ultraviolet irradiationinduced melanoma differs in clinical presentation,

Correspondence: Dr S Aulmann, PD, Gemeinschaftspraxis für Pathologie, Ginnheimer Landstraße 86, 60487 Frankfurt, Germany. E-mail: s.aulmann@pathologie-frankfurt.de

${ }^{7}$ These authors contributed equally to this work.

Received 24 June 2013; revised 6 October 2013; accepted 6 October 2013; published online 7 March 2014 location, and underlying biological alterations from non-sun-induced tumors. Furthermore, melanomas arising in different mucosal sites have been shown to differ not only from cutaneous tumors but also from site to site with a substantial heterogeneity of alterations in a number of genes, some of which such as BRAF or KIT may be targeted by specific pharmacological inhibitors.

In the present study, we evaluated a large series of melanomas arising in the female genital tract and assessed mutations of the BRAF, NRAS, KIT, and EGFR genes as well as KIT amplifications.

\section{Materials and Methods}

A total of 65 primary malignant melanomas of the vulva or vagina were collected from the archives of the Pathology Department at Vancouver General 
Table 1 Clinical, pathological and molecular features of 50 vulvar melanomas

\begin{tabular}{|c|c|c|c|c|c|c|c|c|c|c|c|c|}
\hline $\begin{array}{l}\text { Case } \\
\text { no. }\end{array}$ & Age & Localization & $\begin{array}{l}\text { Tumor } \\
\text { type }\end{array}$ & $\begin{array}{l}\text { Ulcera- } \\
\text { tion }\end{array}$ & $\begin{array}{l}\text { Cellu- } \\
\text { larity }\end{array}$ & $\begin{array}{l}\text { Pigmen- } \\
\text { tation }\end{array}$ & $\begin{array}{l}\text { Tumor } \\
\text { depth }^{\mathrm{c}}\end{array}$ & $\begin{array}{l}\text { Lymph } \\
\text { node } \\
\text { status }\end{array}$ & $\begin{array}{l}\text { Molecular } \\
\text { findings }\end{array}$ & $\begin{array}{c}K I T \\
I H C^{\mathrm{d}}\end{array}$ & $\begin{array}{l}\text { Follow-up } \\
\text { time }\end{array}$ & $\begin{array}{l}\text { Follow-up } \\
\text { status }^{\mathrm{f}}\end{array}$ \\
\hline 1 & 81 & Clitoris & MLM & - & $\mathrm{E}$ & + & 3.8 & n.i. & & +++ & n.i. & n.i. \\
\hline 2 & 73 & Clitoris & NM & + & $\mathrm{E}$ & + & 1.4 & n.i. & & ++ & n.i. & n.i. \\
\hline 3 & 76 & Clitoris & MLM & + & $\bar{S}$ & + & 1.2 & $0 / 22$ & & +++ & 188 & $\mathrm{~A} / \mathrm{L}$ \\
\hline 4 & 68 & Clitoris & SSM & - & $\mathrm{E}$ & + & 1.1 & $0 / 1$ & & ++ & 3 & $\mathrm{~A} / \mathrm{L}$ \\
\hline 5 & 83 & Clitoris & NM & + & $\mathrm{E}$ & - & 20.5 & $0 / 14$ & $\begin{array}{l}\text { NRAS Q61L, Kit } \\
\text { amplification }\end{array}$ & ++ & 3 & DOD \\
\hline 6 & 76 & Clitoris/paraclitorial & MLM & n.d. & n.d. & + & n.d. & $0 / 1$ & & ++ & n.i & n.i \\
\hline 7 & 73 & Clitoris and bilateral labia & MLM & + & S & - & 9.5 & $0 / 16$ & & + & 23 & DOD \\
\hline 8 & 66 & Paraclitorial & SSM & - & $\mathrm{E}$ & + & 2.1 & $0 / 4$ & & + & 129 & DOD \\
\hline 9 & 74 & Introitus & NM & - & $\mathrm{E}$ & - & 5 & $0 / 19$ & & + & 2 & $\mathrm{~A} / \mathrm{L}$ \\
\hline 10 & 73 & Introitus & NM & + & $\mathrm{E}$ & + & 3.4 & $0 / 16$ & KIT V560D & +++ & 13 & DOD \\
\hline 11 & 78 & Introitus & NM & + & $\mathrm{E}$ & - & 12.4 & n.i. & KIT amplification & +++ & 40 & DOD \\
\hline 12 & 66 & Introitus & NM & + & $\mathrm{E}$ & + & 12 & $2 / 9$ & & ++ & 11 & DOD \\
\hline 13 & 84 & $\begin{array}{l}\text { Introitus, both labiae } \\
\text { minorae and majorae }\end{array}$ & NM & + & $\mathrm{E}$ & - & 9 & n.i. & & + & 8 & DOD \\
\hline 14 & 87 & Left labia minora & NM & + & $\mathrm{E}$ & - & 4 & n.i. & & + & 1 & $\mathrm{~A} / \mathrm{L}$ \\
\hline 15 & 71 & Left labia minora & MLM & + & $\mathrm{S}$ & - & 13 & n.i. & KIT amplification & +++ & 12 & $\mathrm{~A} / \mathrm{L}$ \\
\hline 16 & 77 & Right labia minora & SSM & - & $\mathrm{E}$ & - & 12 & n.i. & & +++ & n.i. & n.i. \\
\hline 17 & 56 & Left labia minora & NM & + & $\mathrm{E}$ & - & 5.5 & $0 / 1$ & & + & 92 & $\mathrm{~A} / \mathrm{L}$ \\
\hline 18 & 56 & Left labia minora & SSM & + & $\mathrm{E}$ & - & 1.2 & $0 / 1$ & KIT D820V & +++ & 28 & DOD \\
\hline 19 & 49 & $\begin{array}{l}\text { Left labia majora/ } \\
\text { junction labia minora }\end{array}$ & MLM & + & $\mathrm{E}$ & - & 2.6 & $4 / 14$ & KIT amplification & ++ & 9 & DOD \\
\hline 20 & 88 & $\begin{array}{l}\text { Right labia minora } \\
\text { and majora }\end{array}$ & NM & + & $\mathrm{E}$ & - & 10.7 & n.i. & & +++ & 25 & DOD \\
\hline 21 & 66 & $\begin{array}{l}\text { Left labia majora/ } \\
\text { junction labia minora }\end{array}$ & MLM & + & $\mathrm{E}$ & - & 4.8 & $0 / 1$ & & - & 24 & $\mathrm{~A} / \mathrm{L}$ \\
\hline 22 & 72 & Right labia majora & MLM & + & $\mathrm{E}$ & + & 9 & n.i. & & ++ & n.i. & n.i. \\
\hline 23 & 74 & Left labia majora & MLM & + & $\mathrm{E}$ & + & 13.1 & $5 / 15$ & & + & 3 & DOD \\
\hline 24 & 60 & Left labia & SSM & - & $\mathrm{E}$ & - & 0.9 & n.i. & & + & n.i. & n.i. \\
\hline 25 & 82 & Right labia & NM & - & $\mathrm{E}$ & + & 11.5 & $1 / 13$ & & - & 9 & DOD \\
\hline 26 & 62 & Right labia & SSM & + & $\mathrm{E}$ & - & 3.4 & n.i. & & + & 39 & DOD \\
\hline 27 & 64 & Left labia & SSM & + & $\mathrm{S}$ & - & 4.7 & $1 / 1$ & KIT W557R & +++ & 51 & DOD \\
\hline 28 & 83 & Right labia & NM & + & $\mathrm{E}$ & - & 9.8 & $0 / 11$ & KIT Y578-H580dup & +++ & 84 & DOD \\
\hline 29 & 74 & Right labia & MLM & - & $\mathrm{E}$ & + & 7.4 & $0 / 6$ & $\begin{array}{l}\text { NRAS Q61L, KIT } \\
\text { P585insREF }\end{array}$ & ++ & 42 & DOD \\
\hline 30 & 77 & No information & NM & + & $\mathrm{E}$ & - & n.d. & n.i. & & + & 3 & DOD \\
\hline 31 & 79 & No information & NM & + & $\mathrm{S}$ & - & 0.5 & n.i. & & - & n.i. & n.i. \\
\hline 32 & 82 & No information & MLM & - & $\mathrm{E}$ & + & 1 & n.i. & & ++ & n.i. & n.i. \\
\hline 33 & 73 & No information & NM & + & $\mathrm{E}$ & - & 10 & n.i. & $\begin{array}{l}\text { NRAS G12A + } \\
\text { KIT R586I }\end{array}$ & +++ & n.i. & n.i. \\
\hline 34 & 61 & No information & NM & n.d. & $\mathrm{E}$ & + & n.d. & $5 / 23$ & & - & 22 & DOD \\
\hline 35 & 72 & No information & NM & - & $\mathrm{E}$ & + & 1.9 & n.i. & & - & n.i. & n.i. \\
\hline 36 & 67 & No information & SSM & - & $\mathrm{E}$ & + & 0.1 & n.i. & & ++ & n.i. & n.i. \\
\hline 37 & 91 & No information & NM & + & $\mathrm{E}$ & + & 2.6 & n.i. & & - & n.i. & n.i. \\
\hline 38 & 92 & No information & NM & + & $S$ & + & 16.4 & n.i. & & ++ & n.i. & n.i. \\
\hline 39 & 86 & No information & NM & + & $\mathrm{E}$ & - & 11.9 & n.i. & NRAS G13D & - & 4 & DOR \\
\hline 40 & 89 & No information & NM & + & $\mathrm{E}$ & + & 10.9 & $1 / 1$ & & ++ & 3 & DOD \\
\hline 41 & 82 & No information & SSM & + & $\mathrm{E}$ & - & 4.1 & $1 / 23$ & KIT V559D & ++ & 7 & DOD \\
\hline 42 & 78 & No information & n.d. & n.d. & $\mathrm{E}$ & + & n.d. & n.i. & & + & 33 & DOD \\
\hline 43 & 40 & No information & NM & - & $\mathrm{E}$ & + & 8.5 & $0 / 13$ & NRAS G12V & - & 18 & DOD \\
\hline 44 & 74 & No information & NM & - & $\mathrm{E}$ & + & 13 & n.i. & & ++ & 10 & DOD \\
\hline 45 & 74 & No information & NM & + & $\mathrm{E}$ & + & 7.2 & $0 / 14$ & & + & 11 & DOD \\
\hline 46 & 68 & No information & NM & + & $\mathrm{E}$ & - & 5.2 & $0 / 1$ & KIT amplification & +++ & 21 & DOD \\
\hline 47 & 85 & No information & n.d. & n.d. & $\mathrm{E}$ & + & n.d. & $1 / 1$ & & + & 8 & DOR \\
\hline 48 & 80 & No information & NM & + & $\mathrm{E}$ & - & 14.6 & n.i. & & - & 71 & DOD \\
\hline 49 & 76 & No information & NM & + & $\mathrm{E}$ & - & 6.6 & n.i. & & ++ & 68 & $\mathrm{~A} / \mathrm{L}$ \\
\hline 50 & 46 & No information & MLM & - & $\mathrm{E}$ & + & 1.5 & $0 / 13$ & & - & 9 & $\mathrm{~A} / \mathrm{L}$ \\
\hline
\end{tabular}

n.d., not determined; n.i., no information.

${ }^{a}$ MLM, mucosal lentiginous melanoma; NM, nodular melanoma; SSM, superficial spreading melanoma.

${ }^{b_{E}}$, epithelioid; S, spindle cell morphology.

CTumor depth (Breslow) in millimeters.

$\mathrm{d}_{\text {KIT immunohistochemistry (semiquantitative). }}$

Eollow-up time in months.

${ }^{f}$ DOD, died of disease; DOR, died for other reasons; A/L alive or lost to follow-up. 
Table 2 Clinical, pathological, and molecular features of 15 vaginal melanomas

\begin{tabular}{|c|c|c|c|c|c|c|c|c|c|c|c|}
\hline $\begin{array}{l}\text { Case } \\
\text { no. }\end{array}$ & Age & $\begin{array}{l}\text { Tumor } \\
\text { type }\end{array}$ & Ulceration & Cellularity $^{\mathrm{b}}$ & $\begin{array}{l}\text { Pigmen- } \\
\text { tation }\end{array}$ & $\begin{array}{l}\text { Tumor } \\
\text { depth }\end{array}$ & $\begin{array}{l}\text { Lymph } \\
\text { node } \\
\text { status }\end{array}$ & Molecular findings & $K I T I H C^{\mathrm{d}}$ & $\begin{array}{l}\text { Follow-up } \\
\text { time }\end{array}$ & $\begin{array}{l}\text { Follow-up } \\
\text { status }^{\mathrm{f}}\end{array}$ \\
\hline 1 & 75 & MLM & + & $\mathrm{E}$ & - & 2 & n.i. & & - & 28 & DOD \\
\hline 2 & 69 & NM & + & $\mathrm{E}$ & - & 10 & n.i. & & + & 13 & DOD \\
\hline 3 & 79 & NM & + & $\mathrm{S}$ & + & 35 & n.i. & & ++ & 12 & DOD \\
\hline 4 & 51 & NM & + & $\mathrm{E}$ & + & 6.8 & n.i. & $\begin{array}{l}\text { NRAS G12V, KIT } \\
\text { amplification }\end{array}$ & - & n.i. & n.i. \\
\hline 5 & 75 & NM & + & $\mathrm{E}$ & - & 9.2 & n.i. & & - & n.i. & n.i. \\
\hline 6 & 65 & NM & + & $\mathrm{E}$ & - & 3.6 & n.i. & & + & n.i. & n.i. \\
\hline 7 & 83 & NM & - & $\mathrm{S}$ & - & 9.8 & n.i. & & - & n.i. & n.i. \\
\hline 8 & 59 & NM & + & $\mathrm{E}$ & - & 3.8 & $0 / 5$ & & - & 117 & $\mathrm{~A} / \mathrm{L}$ \\
\hline 9 & 74 & SSM & - & $\mathrm{E}$ & + & 11.3 & n.i. & $\begin{array}{l}\text { Heterogeneous KIT } \\
\text { amplification (sub-clone) }\end{array}$ & $\begin{array}{c}-/+++ \\
\text { (sub- } \\
\text { clone) }\end{array}$ & 23 & DOD \\
\hline 10 & 76 & NM & + & $\mathrm{E}$ & - & 4.5 & n.i. & & + & 14 & DOD \\
\hline 11 & 78 & NM & + & $\mathrm{E}$ & - & 6.1 & n.i. & NRAS Q61H & - & 6 & DOD \\
\hline 12 & 73 & NM & - & $\mathrm{E}$ & - & 5.6 & n.i. & & + & 16 & DOD \\
\hline 13 & 50 & NM & + & $\mathrm{E}$ & - & 11 & $0 / 10$ & & - & 8 & DOD \\
\hline 14 & 64 & NM & + & $\mathrm{E}$ & - & 26 & $0 / 3$ & & - & 19 & DOD \\
\hline 15 & 76 & NM & + & $\mathrm{E}$ & + & 14.8 & n.i. & & - & 28 & DOD \\
\hline
\end{tabular}

n.d., not determined; n.i., no information.

${ }^{a}$ MLM, mucosal lentiginous melanoma; NM, nodular melanoma; SSM, superficial spreading melanoma.

$\mathrm{b}_{\mathrm{E}}$, epithelioid; $\mathrm{S}$, spindle cell morphology.

${ }^{\mathrm{C}}$ Tumor depth (Breslow) in millimeters.

d KIT immunohistochemistry (semiquantitative).

e Follow-up time in months.

${ }^{\mathrm{f}} \mathrm{DOD}$, died of disease; DOR, died for other reasons; A/L alive or lost to follow-up.

Hospital, Vancouver, British Columbia, Canada (39 cases diagnosed between 1985 and 2010), the Institute of Pathology, A2,2, Mannheim, Germany (16 cases diagnosed between 2000 and 2010) and the Institute of Pathology of the University Hospital, Heidelberg Germany (10 cases diagnosed between 1998 and 2012). Patients with a history of extragenital melanoma or with synchronous extragenital melanomas detected on clinical examination were excluded. Of the 65 tumors, 50 were located on the vulva and 15 originated in the vagina. The slides were reviewed for tumor depth according to Breslow, tumor type (superficial spreading, mucosal lentiginous or nodular), the presence of ulceration or pigmentation and the predominant cell type (epitheloid or spindle cell). Follow-up information was available in 48 cases (median follow-up 15 months, range 1-188 months), within this time, 35 patients had died of disease, 11 were alive, and 2 had died of unrelated causes.

KIT immunostains were performed according to standard procedures. In brief, deparaffinized slides were subjected to heat-induced epitope retrieval (citrate buffer, $\mathrm{pH}$ 6.0, Dako, Hamburg, Germany) followed by incubation with a polyclonal KIT antiserum (Dako) at a dilution of 1:50. For visualization, a modified avidin-biotin-complex method was employed using the LSAB + Kit (Dako) according to the manufacturer's instructions.

For PCR analysis, tumor tissue was microdissected using glass capillaries and digested as described previously. ${ }^{4}$ After heat inactivation of the enzyme, the lysate was directly used for PCR under standard conditions using previously published primer combinations for NRAS (exons 2 and $3,^{5}$ ), BRAF (exon 15, ${ }^{5}$ ), KIT (exons 11, 13, 17, and $18,{ }^{6}$ ) and $E G F R$ (exons 18, 19, 20, and $21,{ }^{4}$ ). PCR products were directly sequenced on an ABI Prism 377 sequencer (Applied Biosystems, Darmstadt, Germany).

To assess copy number alterations of the KIT gene, a fluorescence in situ hybridization (FISH) probe was generated from BAC clones RP11-586A2 and RP11-273B19 (obtained from Imagenes, Berlin, Germany). In brief, BAC-DNA was isolated (Maxi Prep Kit, Quiagen, Hilden, Germany), fragmented using sonification and fluorescent-labeled using the Platinum Bright 547 nucleic acid labeling kit (Kreatech, Amsterdam, Netherlands). Following coprecipitation of the probe with COT1-DNA (Roche, Mannheim, Germany), the DNA mixture was hybridized onto pre-treated paraffin sections of the tumors as described previously. ${ }^{7}$

\section{Results}

Patient and tumor characteristics are summarized in Tables 1-3. The average patient age at the time of diagnosis was 72 years (range, 40-89 years). The predominant growth pattern was nodular $(63 \%)$ followed by mucosal lentiginous (21\%), and superficial spreading $(16 \%)$. Ulceration was present in $72 \%$ of cases. In all, 59 of 65 cases (91\%) showed an 
Table 3 Comparison of clinical and pathological features between vulvar and vaginal melanomas

\begin{tabular}{|c|c|c|c|c|}
\hline $\mathrm{n}$ & $\begin{array}{c}\text { Total } \\
65\end{array}$ & $\begin{array}{c}\text { Vulvar } \\
\text { melanomas } \\
50\end{array}$ & $\begin{array}{c}\text { Vaginal } \\
\text { melanomas } \\
15\end{array}$ & $\mathrm{P}$ \\
\hline Average patient age & 72.5 & 73.3 & 69.8 & 0.296 \\
\hline \multicolumn{5}{|l|}{ Tumor type } \\
\hline Superficial spreading & $10(16 \%)$ & $9(19 \%)$ & $1(7 \%)$ & \\
\hline Mucosal lentiginous & $13(21 \%)$ & $12(25 \%)$ & $1(7 \%)$ & \\
\hline Nodular & $40(63 \%)$ & $27(56 \%)$ & $13(87 \%)$ & \\
\hline Not determined & 2 & 2 & 0 & 0.016 \\
\hline \multicolumn{5}{|l|}{ Ulceration } \\
\hline Absent & $17(28 \%)$ & $14(30 \%)$ & $3(20 \%)$ & \\
\hline Present & $44(72 \%)$ & $32(70 \%)$ & $12(80 \%)$ & 0.524 \\
\hline Not determined & 4 & 4 & 0 & \\
\hline \multicolumn{5}{|l|}{ Growth pattern } \\
\hline Polypoid/exophytic & $42(69 \%)$ & $32(70 \%)$ & $10(67 \%)$ & \\
\hline Flat & 19 (31\%) & $14(30 \%)$ & $5(33 \%)$ & 0.745 \\
\hline Not determined & 4 & 4 & 0 & \\
\hline \multicolumn{5}{|l|}{ Cellularity } \\
\hline Epitheloid & 59 (91\%) & $44(88 \%)$ & $15(100 \%)$ & 0.480 \\
\hline Spindle-cell & $6(9 \%)$ & $6(12 \%)$ & 0 & \\
\hline \multicolumn{5}{|l|}{ Pigment production } \\
\hline Absent & $35(54 \%)$ & $24(48 \%)$ & $11(73 \%)$ & \\
\hline Present & $30(46 \%)$ & $26(52 \%)$ & $4(27 \%)$ & 0.150 \\
\hline \multicolumn{5}{|l|}{ Tumor depth } \\
\hline$<0.75 \mathrm{~mm}$ & 2 & 2 & 0 & \\
\hline $0.75-1.49 \mathrm{~mm}$ & 6 & 6 & 0 & \\
\hline $1.50-2.49 \mathrm{~mm}$ & 4 & 3 & 1 & \\
\hline $2.50-3.49 \mathrm{~mm}$ & 4 & 4 & 0 & \\
\hline $3.50-4.99 \mathrm{~mm}$ & 8 & 5 & 3 & \\
\hline $5.00-9.99 \mathrm{~mm}$ & 18 & 11 & 5 & \\
\hline$>=10 \mathrm{~mm}$ & 18 & 14 & 6 & 0.613 \\
\hline Not determined & 5 & 5 & 0 & \\
\hline \multicolumn{5}{|l|}{ Lymph node status } \\
\hline Negative & 20 & 17 & 3 & \\
\hline Positive & 8 & 9 & 0 & 0.532 \\
\hline No information & 37 & 24 & 12 & \\
\hline
\end{tabular}

epithelioid morphology, spindle cell differentiation was seen in 6 tumors. Production of melanin was observed in 30 tumors (46\%), the majority of cases were deeply infiltrative (36 of 60 informative cases, $60 \%$ ), a tumor depth of $>10 \mathrm{~mm}$ was seen in 18 cases $(30 \%)$. Tumor depth and the presence of lymph node metastases were significantly associated with poorer patient outcome (overall survival) in univariate analysis (Figure 1); multivariate analysis was not performed owing to the low numbers of patients. Vulvar melanomas differed from tumors originating within the vagina with respect to the growth pattern. The superficial spreading and mucosal lentiginous types were significantly associated with vulvar location while most vaginal tumors were nodular melanomas $(P=0.016)$. In addition, spindle cell morphology was only seen in six tumors of the vulva. Vaginal tumors showed a tendency toward greater tumor depth, but these differences failed to reach significance (Table 3). Typical histological features, exemplary immunostains and FISH results are shown in Figure 2.

The immunohistochemical and molecular findings are summarized in Table 4. Using immunohistochemistry, moderate or strong cytoplasmic KIT expression was detected in 30 of the 65 cases (46\%). In 54 cases, KIT sequence analysis was successfully performed revealing four exon 11 point mutations (W557R, V559D, V560D, and R586I), two exon 11 insertions (Y578-H580dup and P585 ins REF), and one exon 17 point mutation (D820V). All of these seven tumors showed strong KIT immunostaining $(P=0.0014)$. Increased KIT gene copy numbers defined as more than four FISH signals per nucleus on average were seen in 7 of 57 successfully hybridized tumors $(12 \%)$, in 4 of the 7 cases more than 10 signals arranged in clusters were observed, whereas in the remaining 3 tumors an average of between 4 and 8 signals was seen. In one of these cases (a deeply infiltrating vaginal melanoma), a high-level KIT amplification resulting in KIT overexpression was observed in approximately half of the tumor cells showing a sharp demarcation from the (superficial) rest of the tumor (Figure 2). No intratumoral heterogeneity was observed in any of the other amplified cases. Six of the seven tumors with increased KIT copy numbers showed moderate or strong KIT staining $(P=0.045)$, whereas one case with an average of 5.5 signals per nucleus was only weakly positive. Seven melanomas harbored NRAS mutations affecting codons 12, 13, or 61 (G12A, $2 \times$ G12V, G13D, $2 \times$ Q61L, and Q61H), no mutations in the sequenced $B R A F$ or EGFR exons were detected. None of the molecular features was associated with patient survival (Figure 3). Although KIT mutations were exclusively observed in vulvar melanomas $(P=0.171)$, KIT amplifications and increased KIT protein levels were seen in both locations. No difference was observed between vulvar and vaginal tumors regarding NRAS mutations.

\section{Discussion}

Over the past years, a surprising molecular heterogeneity of malignant melanoma has emerged. Activating V600E or V600K mutations in the BRAF kinase have been observed in up to $62 \%$ of melanomas arising in sun-exposed skin. ${ }^{8}$ Targeting BRAF using specific inhibitors such as dabrafenib or vemurafenib has led to substantially increased survival rates in BRAF mutated, but not in BRAF wild-type melanoma. ${ }^{9,10}$ However, in melanomas arising on mucosal surfaces or non-sun-exposed skin, $B R A F$ mutations have only infrequently been reported. ${ }^{8}$ Accordingly, none of the gynecological melanomas in our series harbored a $B R A F$ mutation.

As somatic BRAF and NRAS mutations are mutually exclusive, ${ }^{11}$ we next screened our series 

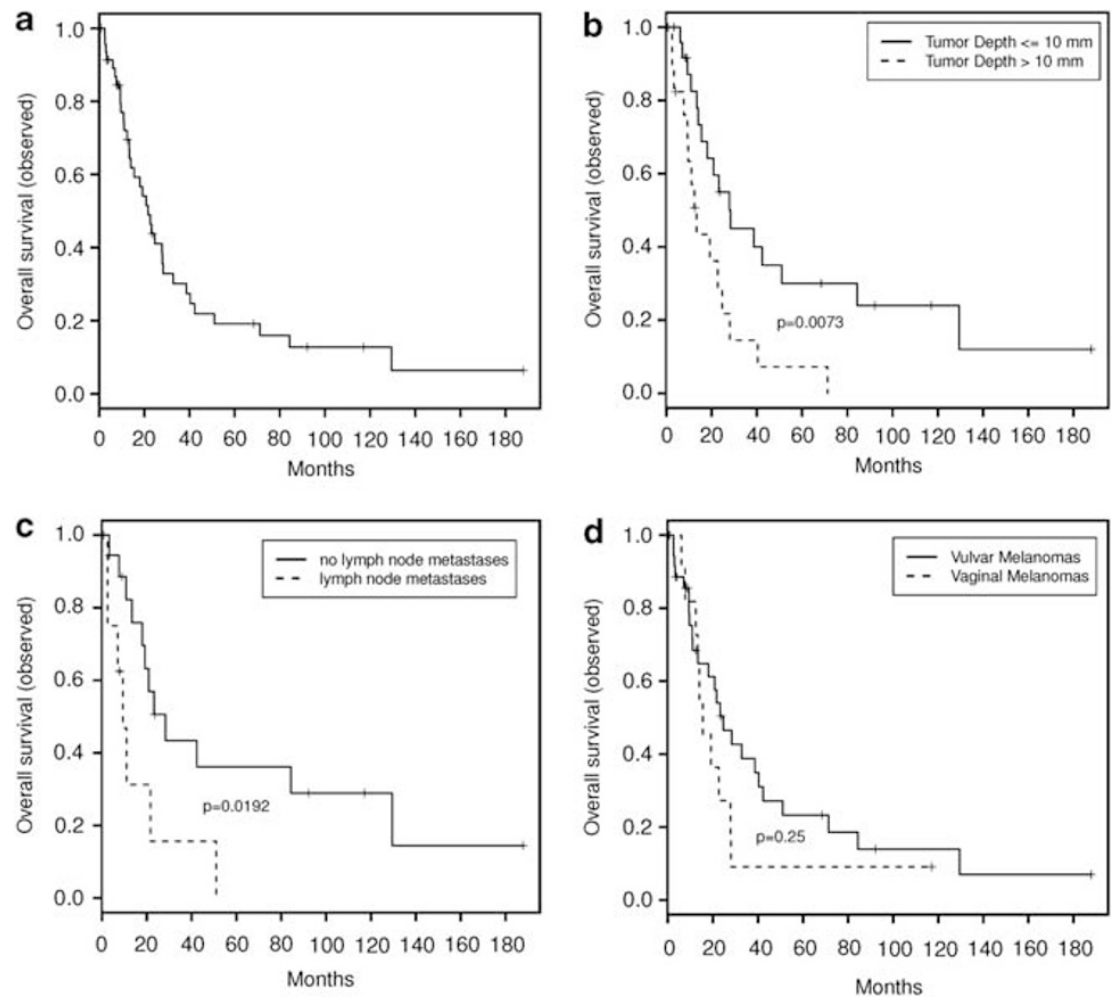

Figure 1 (a) Overall survival for all patients with vulvar or vaginal melanomas. Greater tumor depth (b) and the presence of lymph node metastases (c) were significantly associated with poorer patient outcome (univariate analysis, log rank test), whereas location (vulva vs vagina) was not (d).

for mutations in exons 2 and 3 (including codons 12, 13, and 61) of NRAS. NRAS mutations were present in four (three vulvar and one vaginal) tumors indicating a mutation frequency of $\sim 12 \%$ in gynecological melanomas which is notably lower than in melanomas arising in chronic sun-damaged skin where mutation rates of up to $24 \%$ have been reported. ${ }^{12}$ Interestingly, in contrast to some TP53, $C C K N 2 A$, or PTEN mutations that also may be present in melanomas, NRAS alterations typically are not classical ultraviolet irradiation-induced $\mathrm{G}: \mathrm{C}>\mathrm{A}: \mathrm{T}$ exchanges or GG:CC $>\mathrm{AA}$ :TT exchanges at dipyrimidine sites which points to a more complex mechanism leading to these mutations. ${ }^{13}$ In fact, in contrast to melanomas in other mucosal sites, esophageal melanomas were reported to harbor NRAS mutations in $>30 \%$ of cases $^{14}$ further underlining the lack of direct association with ultraviolet irradiation. Recently, MEK-inhibition was shown to demonstrate therapeutic activity in NRAS-mutated melanoma opening a novel therapeutic option for these tumors. ${ }^{15}$

KIT mutations and amplifications have been observed in varying frequencies in melanomas arising from different primary sites. ${ }^{16-18}$ In addition, KIT protein expression or overexpression as detected by immunohistochemistry has been reported to show some correlation with KIT mutations or amplifications ${ }^{16}$ but has been insufficient to predict response to KIT-targeted therapy with imatinib. ${ }^{19}$ In a recent phase II study, response rates for metastatic melanomas treated with imatinib mesylate were $64.7 \%$ in patients with KIT exon 11 mutations, $40 \%$ for exon 17 mutations, and 33\% for KIT amplifications. ${ }^{20}$ The frequency of KIT mutations in mucosal melanomas has been reported to be as high as $39 \% .{ }^{16}$ We observed five KIT point mutations (exons 11 and 17) and two in-frame insertions (exon 11) in vulvar melanomas, but none in vaginal tumors indicating an important difference in the underlying biology. Although some authors interpret vulvar tumors as melanomas of the nonsun-exposed skin, ${ }^{8}$ vaginal melanomas show molecular and morphological similarities to esophageal primaries $^{14}$ that typically lack KIT mutations but may harbor NRAS alterations.

In conclusion, malignant melanomas of the vulva and vagina typically are aggressive tumors associated with a poor overall survival. Tumors in both locations frequently are deeply infiltrating at the time of diagnosis, highlighting the need for novel adjuvant treatment approaches. As overall survival in patients with gynecological melanomas is very poor, our data provide a rationale for KIT mutation testing and targeted treatment approaches in melanomas of the vulva. Targeting of NRAS-mutated tumors with MEK inhibitors may be beneficial in melanomas of the vulva and vagina. 
a

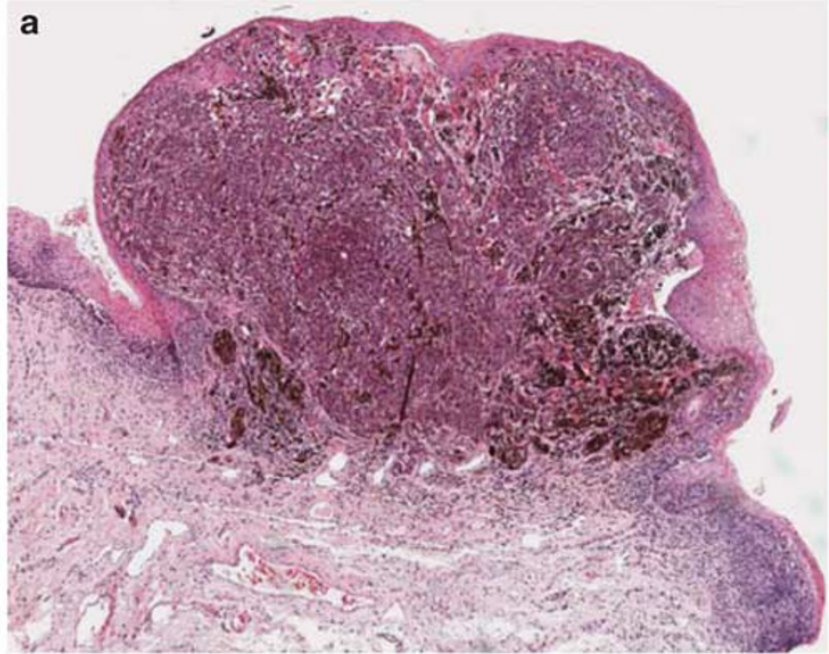

C
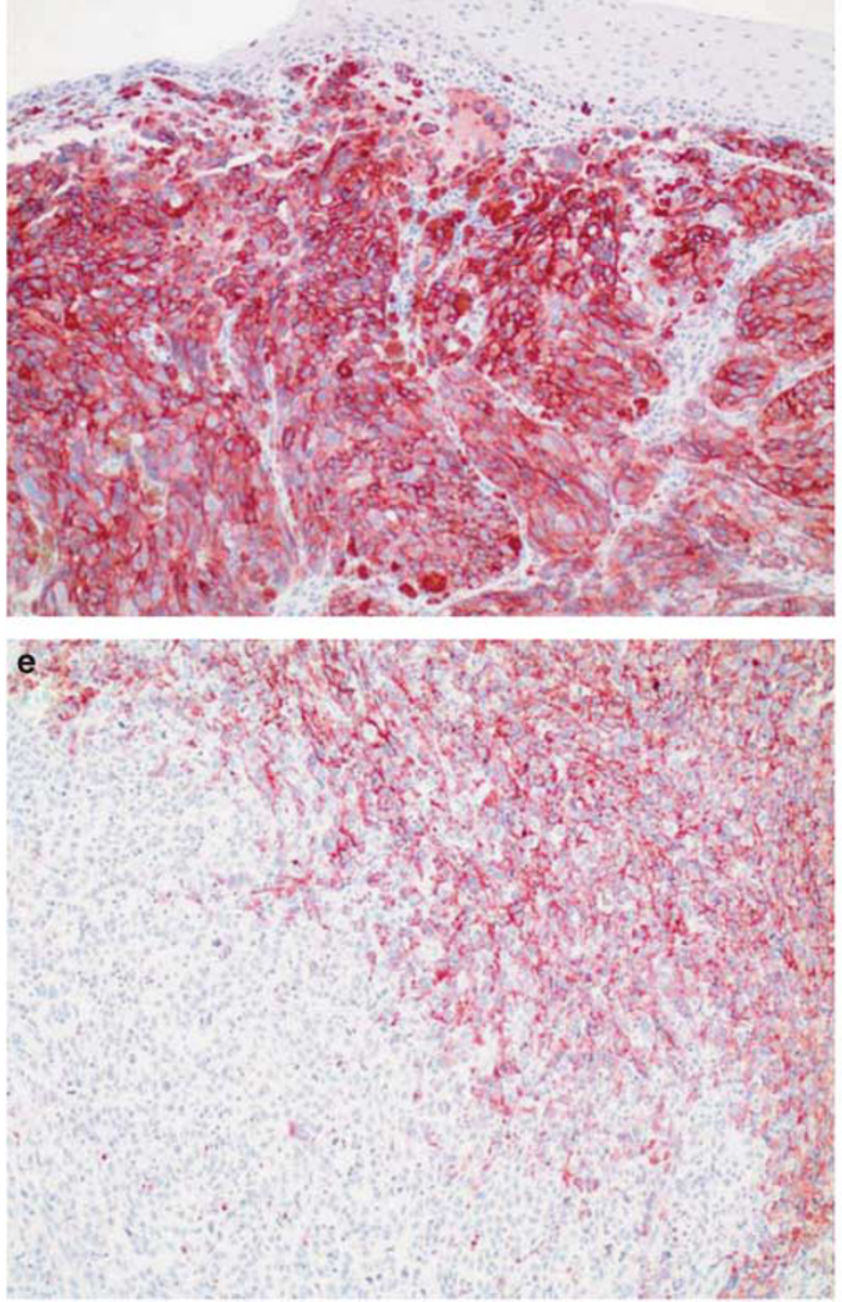
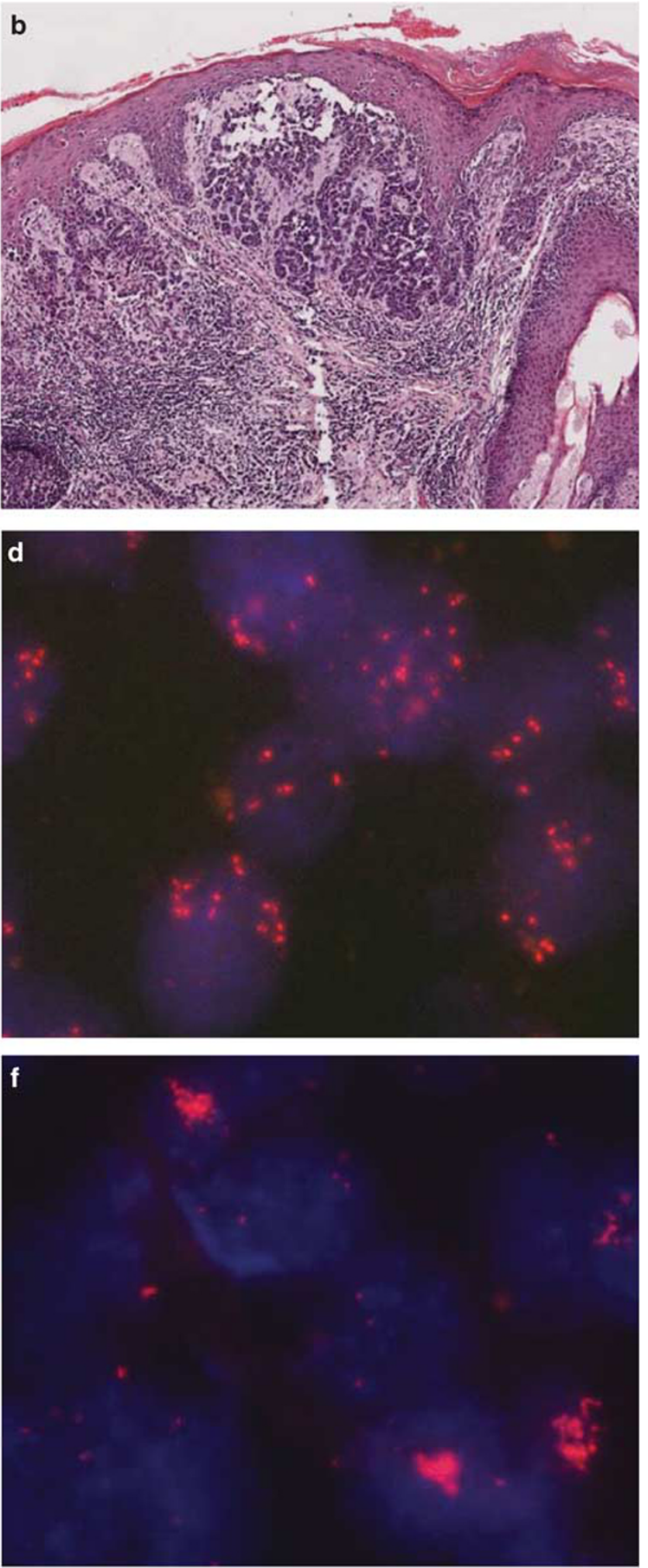

Figure 2 Representative histology of a nodular ((a) hematoxylin and eosin, original magnification $\times 40)$ and mucosal lentiginous melanoma ((b) hematoxylin and eosin, original magnification $\times 100)$. (c,d) KIT overexpression ((c) KIT-Immunostain, original magnification $\times 100)$ and amplification $((\mathbf{d})$ FISH, original magnification $\times 1000)$ in a case of vulvar melanoma (case 28). $(\mathbf{e , f})$ Heterogeneous KIT overexpression (KIT-IHC, original magnification $\times 100$ ) and amplification $($ FISH, original magnification $\times 1000)$ in a malignant melanoma of the vagina (case 9). 
Table 4 Comparison of immunohistochemical and molecular findings between vulvar and vaginal melanomas

\begin{tabular}{|c|c|c|c|c|}
\hline & Total & Vulvar melanomas & Vaginal melanomas & $\mathrm{P}$ \\
\hline \multicolumn{5}{|l|}{ KIT IHC ${ }^{\mathrm{a}}$} \\
\hline Negative/weak & $35(54 \%)$ & $22(44 \%)$ & $13(87 \%)$ & \\
\hline Positive & $30(46 \%)$ & $28(56 \%)$ & $2(13 \%)$ & 0.007 \\
\hline \multicolumn{5}{|c|}{ KIT sequencing analysis (exons 11, 13, 15, and 17) } \\
\hline Wild type & $47(87 \%)$ & $32(82 \%)$ & $15(100 \%)$ & \\
\hline Mutation & $7(13 \%)$ & $7(18 \%)$ & 0 & 0.171 \\
\hline Not informative & 11 & 11 & 0 & \\
\hline \multicolumn{5}{|l|}{ KIT FISH $H^{\mathrm{b}}$} \\
\hline No amplification & $50(88 \%)$ & $37(88 \%)$ & $13(87 \%)$ & \\
\hline Amplification & $7(12 \%)$ & $5(12 \%)$ & $2(13 \%)$ & 1 \\
\hline Not informative & 8 & 8 & 0 & \\
\hline \multicolumn{5}{|l|}{ NRAS exons $2 / 3$} \\
\hline Wild type & $50(88 \%)$ & $37(88 \%)$ & $13(87 \%)$ & \\
\hline Mutation & $7(12 \%)$ & $5(12 \%)$ & $2(13 \%)$ & 1 \\
\hline Not informative & 8 & 8 & 0 & \\
\hline \multicolumn{5}{|l|}{ BRAF exon 15} \\
\hline Wild type & $54(100 \%)$ & $39(100 \%)$ & $15(100 \%)$ & \\
\hline Mutation & 0 & 0 & 0 & \\
\hline Not informative & 11 & 11 & 0 & \\
\hline \multicolumn{5}{|c|}{ EGFR exons $18,19,20$, and 21} \\
\hline Wild type & $45(100 \%)$ & $30(100 \%)$ & $15(100 \%)$ & \\
\hline Mutation & 0 & 0 & 0 & \\
\hline Not informative & 20 & 20 & 0 & \\
\hline
\end{tabular}

${ }^{\mathrm{a}} \mathrm{IHC}$, immunohistochemistry.

bISH, fluorescence in situ hybridization.
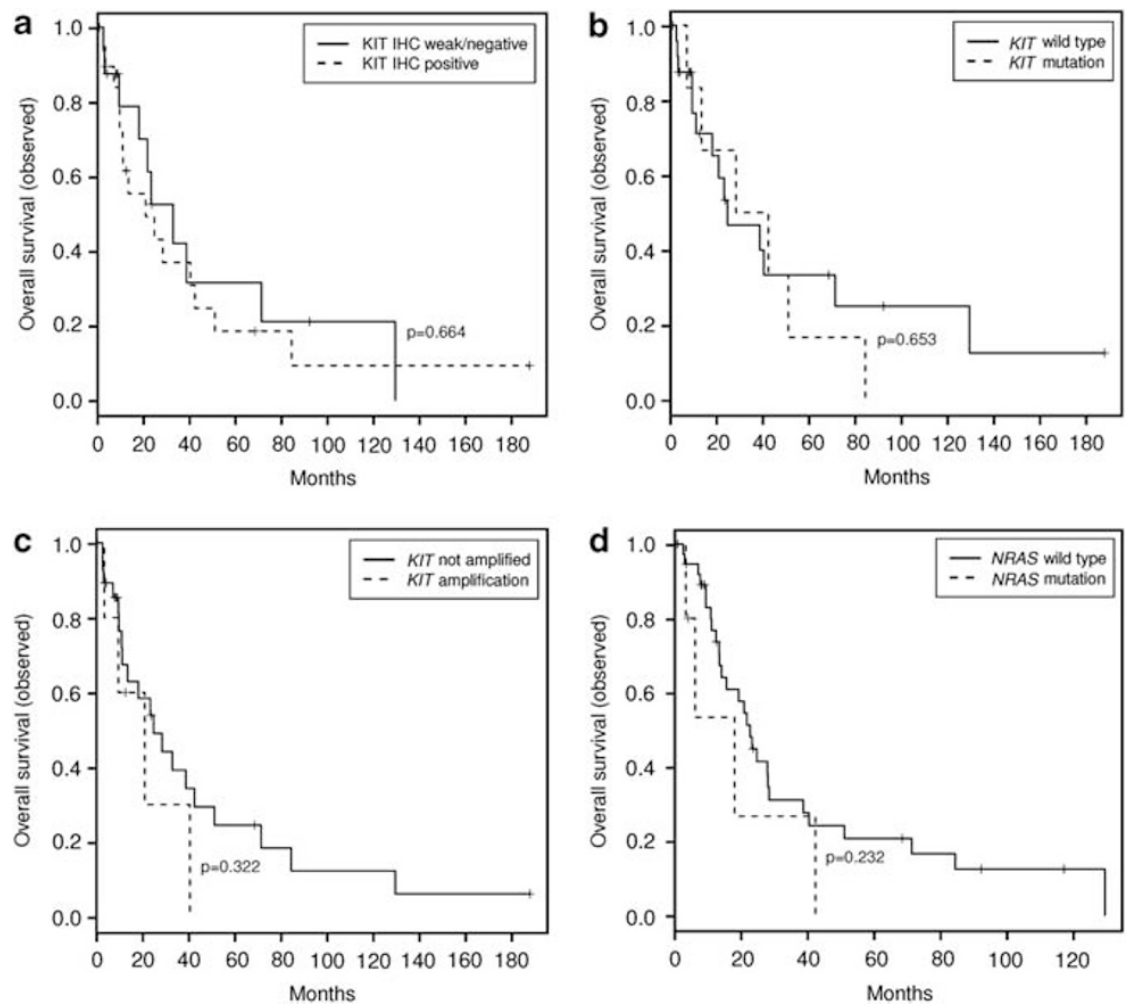

Figure 3 Neither KIT alterations (overexpression (a), mutation (b), or amplification (c)) nor NRAS mutations (d) are associated with a significantly better or worse overall survival (univariate analysis, log-rank test). 


\section{Disclosure/conflict of interest}

The authors declare no conflict of interest.

\section{References}

1 Stang A, Streller B, Eisinger B, et al. Population-based incidence rates of malignant melanoma of the vulva in Germany. Gynecol Oncol 2005;96:216-221.

2 Ragnarsson-Olding BK, Nilsson BR, Kanter-Lewensohn LR, et al. Ringborg UK.Malignant melanoma of the vulva in a nationwide, 25-year study of 219 Swedish females: predictors of survival. Cancer 1999;86: 1273-1284.

3 Tcheung WJ, Selim MA, Herndon JE II, et al. Clinicopathologic study of 85 cases of melanoma of the female genitalia. J Am Acad Dermatol 2012;76: 598-605.

4 Warth A, Macher-Goeppinger S, Muley $\mathrm{T}$, et al. Clonality of multifocal non-small cell lung cancer: implications for staging and therapy. Eur Respir J 2011;39:1437-1442.

5 Davies H, Bignell GR, Cox C, et al. Mutations of the BRAF gene in human cancer. Nature 2002;417:949-954.

6 Penzel R, Aulmann S, Moock M, et al. The location of KIT and PDGFRA gene mutations in gastrointestinal stromal tumours is site and phenotype associated. J Clin Pathol 2005;58:634-639.

7 Aulmann S, Longerich T, Schirmacher P, et al. Detection of the ASPSCR1/TFE3 gene fusion in paraffin embedded alveolar soft part sarcomas. Histopathology 2007;50:881-886.

8 Cohen Y, Rosenbaum E, Begum S, et al. Exon 15 BRAF mutations are uncommon in melanomas arising in nonsun-exposed sites. Clin Cancer Res 2004;10: 3444-3447.

9 Falchook GS, Long GV, Kurzrock R, et al. Dabrafenib in patients with melanoma, untreated brain metastases, and other solid tumours: a phase 1 dose-escalation trial. Lancet 2012;379:1893-1901.
10 Menzies AM, Haydu LE, Visintin L, et al. Distinguishing clinicopathologic features of patients with V600E and V600K BRAF-mutant metastatic melanoma. Clin Cancer Res 2012;18:3242-3249.

11 Palmieri G, Casula M, Sini MC, et al. Issues affecting molecular staging in the management of patients with melanoma. J Cell Mol Med 2007;11:1052-1068.

12 Van Elsas A, Zerp SF, van der Flier S, et al. Relevance of ultraviolet-induced N-ras oncogene point mutations in development of primary human cutaneous melanoma. Am J Pathol 1996;149:883-893.

13 Hocker T, Taso H. Ultraviolet radiation and melanoma: a systematic review and analysis of reported sequence variants. Hum Mutation 2007;28:578-588.

14 Sekine S, Nakanishi Y, Ogawa R, et al. Esophageal melanomas harbor frequent NRAS mutations unlike melanomas of other mucosal sites. Virchows Arch 2009;454:513-517.

15 Ascierto PA, Schadendorf D, Berking C, et al. MEK162 for patients with advanced melanoma harbouring NRAS or Val600 BRAF mutations: a non-randomised, open-label phase 2 study. Lancet Oncol 2013;14: 249-256.

16 Curtin JA, Busam K, Pinkel D, et al. Somatic activation of KIT in distinct subtypes of melanoma. J Clin Oncol 2006;24:4340-4346.

17 Satzger I, Schaefer T, Kuettler U, et al. Analysis of c-KIT expression and KIT gene mutation in human mucosal melanomas. Br J Cancer 2008;99:2065-2069.

18 Omholt K, Grafström E, Kanter-Lewensohn L, et al. KIT pathway alterations in mucosal melanomas of the vulva and other sites. Clin Cancer Res 2011;17: 3933-3942.

19 Alexis JB, Martinez AE, Lutzky J. An immunohistochemical evaluation of c-kit (CD-117) expression in malignant melanoma, and resulst of imatinib mesylate (Gleevec) therapy in three patients. Melanoma Res 2005;15:283-285.

20 Guo J, Si L, Kong Y, et al. Phase II, open-label, singlearm trial of imatinib mesylate in patients with metastatic melanoma harboring c-Kit mutation or amplification. J Clin Oncol 2011;29:2904-2909. 